\section{PRINT ISSN 1119-8362}

Electronic ISSN 1119-8362
Full-text Available Online at

https://www.ajol.info/index.php/jasem

http://ww.bioline.org.br/ja
J. Appl. Sci. Environ. Manage.

Vol. 23 (6) 1007-1011 June 2019

\title{
Design and Fabrication of a Simple Pedal Operated Cassava Grater Suitable for Rural Dwellers
}

\author{
*YUSUF, KO; ${ }^{1}$ AKPENPUUN, TD; ${ }^{2}$ IYANDA, MO \\ Department of Agricultural and Biosystems Engineering, University of Ilorin, Ilorin, Nigeria \\ *Corresponding Author Email: kamaru.yusuf@yahoo.com; yusuf.ok@unilorin.edu.ng; Other Emails: tdenen@gmail.com; \\ akpenpuun.td@unilorin.edu.ng; iyandamo@yahoo.com; iyanda.mo@unilorin.edu.ng
}

\begin{abstract}
Food crop in Nigeria is mainly produced by farmers in the rural areas where petrol/diesel for operating engine, electricity and machines for processing agricultural produce are lacking and this usually result to loss of agricultural produce on the farm before and after harvesting. This study was embarked upon to develop a simple pedal operated cassava grater for rural dwellers. The cassava grater was fabricated using locally available materials mainly hardwood for constructing the frame, grating chamber (hopper), grating roller and the outlet. Iron rod of $20 \mathrm{~mm}$ in diameter (mild steel) for the shaft, three roller bearings, driven and driver pulleys, belt, bicycle pedal and galvanized sheet $(2 \mathrm{~mm}$ in thickness) for the grating surface on the grating roller. The frame of the cassava grater was $540 \mathrm{~mm}$ wide, $1200 \mathrm{~mm}$ long and $1050 \mathrm{~mm}$ high and the grater is portable. The grating chamber was 420 by $440 \mathrm{~mm}$ at the top where the cassava is fed into the grater and 220 by $440 \mathrm{~mm}$ at the bottom inside which the grating roller $(190 \mathrm{~mm}$ diameter and $300 \mathrm{~mm}$ long) grate the cassava into granules. The grating efficiency and capacity of the grater were $90.91 \%$ and $103.7 \mathrm{~kg} / \mathrm{h}$, respectively. The cassava grater could be used for grating cassava tubers in rural areas where electricity and petrol are lacking.
\end{abstract}

\section{DOI: $\underline{\text { https://dx.doi.org/10.4314/jasem.v23i6.2 }}$}

Copyright: Copyright (C) 2019 Yusuf et al. This is an open access article distributed under the Creative Commons Attribution License (CCL), which permits unrestricted use, distribution, and reproduction in any medium, provided the original work is properly cited.

Dates: Received: 10 May 2019; Revised: 15 June 2019; Accepted 20 June 2019

Keywords: cassava grater, cassava processing, shaft design, belt transmission

Cassava (Manihot Esculenta) is a root tuber crop as the tuber develops from the root unlike yam (a stem tuber) which develops from the stem (Omoniyi et al., 1991). It is a source of carbohydrate; it contains some vitamins such as $\mathrm{A}$ and $\mathrm{C}$ and also contains phosphorus and iron (Omoniyi et al., 1991). Cassava is commonly grown in the Southern part of Nigeria. It is tolerant of poor soils but grows better on a well-drained sandy loam soil. Cassava is propagated by stem and the tuber is normally processed to some forms of food such as garri, akpu (fufu) and cassava flour which contain mainly carbohydrate a major source of energy. Cassava tuber contains hydrocyanic acid which is dangerous to human health (Omoruyi et al., 1991). This acid can be removed through proper processing of the cassava tuber. The major part of processing cassava tuber into garri after peeling and washing the tuber is "grating". Grating is milling or grinding of cassava tuber into smaller units (granules) by scratching and rubbing the tuber against a rough metal sheet in order to increase the surface area of the tuber and ease removal of water that contains hydrocyanic acid during dewatering/fermentation process. The grating process is manual and usually done by women in the rural areas using a primitive method by scratching and rubbing cassava tubers against a sharp and rough metallic plate. This grating method is cumbersome, time consuming and can result in injury to the hands. Cassava tuber must be processed 2-3 days after harvesting otherwise it would get spoil (Adetunji and Quadri, 2011). Fermentation of the grated cassava is done after grating the cassava tuber by putting it in a muslin bag and compressed for 2-3 days. This is done to remove or reduce the hydrocyanic acid content in the cassava tuber and also to give the normal taste of garri. The fermented cassava is sieved through a screen of 1 to $2 \mathrm{~mm}$ in diameter, fried by stirring inside a hot frying pan in order to expel water and produce garri. Therefore, grating of cassava tubers is necessary in order to produce garri and it is one of the methods of increasing the shelf-life cassava. The objective of this study was to design and fabricate a simple pedal operated cassava grater for the rural dwellers. Understanding the theory for the design of shaft is very important to prevent failure of the shaft during the operation of a machine. This is achieved by designing and calculating the appropriate diameter of the shaft that could withstand stresses due to torsional and bending moments. Shear stresses due to torsion, torque causing failure due to twisting and section modulus of the shaft was determined using Equations (1), (2) and

*Corresponding AuthorEmail: kamaru.yusuf@yahoo.com; yusuf.ok@unilorin.edu.ng 
(3), respectively as given by (Khurmi and Gupta, 2005).

$$
\begin{gathered}
\tau_{x y}=\frac{T}{Z_{t}} \\
T=\frac{60 P}{2 \pi N} \\
Z_{t}=\frac{\pi d^{3}}{16}
\end{gathered}
$$

where $\tau_{\mathrm{xy}}$ is the shear stress due to torsion $\left(\mathrm{N} / \mathrm{m}^{2}\right), \mathrm{T}$ is the torque $(\mathrm{Nm}), \mathrm{Z}_{\mathrm{t}}$ is the section modulus of the shaft $\left(\mathrm{m}^{3}\right), \mathrm{P}$ is the power of the motor or human power (W), $\mathrm{N}$ is the speed of the motor in revolution per minute (rpm), $\mathrm{d}$ is the diameter of the shaft $(\mathrm{m})$ and $\pi$ $=3.142$.

Bending moment occurs due to the forces acting on the shaft such as the weight of the material to be grated, and pulley on the shaft and the self-weight of the shaft, all in Newton $(\mathrm{N})$. The bending moment for a cantilever support with a concentrated load, a simple support with point load and a simple support with uniformly distributed load could be determined using Equations( 4), (5) and (6), respectively as given by (Chakraborti, 2001; Khurmi and Gupta, 2005).

$$
\begin{aligned}
& M_{b}=W L \\
& M_{b}=\frac{W L}{4} \\
& M_{b}=\frac{W L^{2}}{8}
\end{aligned}
$$

Where $\mathrm{M}_{\mathrm{b}}$ is the bending moment $(\mathrm{Nm}), \mathrm{W}$ is the weight due to point load (concentrated load) or uniformly distributed load (N) and L is the length of the shaft (m).

Computation of the diameter of a shaft is very important. Equation (7) was derived from Equations (1), (2) and (3) when combined with the stress from bending moment using Equation (5) or (6) and considering the factor of safety for a torsional moment $\left(\mathrm{k}_{\mathrm{t}}\right)$ and bending moment $\left(\mathrm{k}_{\mathrm{b}}\right)$. Therefore, the diameter of a solid shaft of any machine having little or no axial loading could be determined using Equation (7) by putting allowable or permissible stress of the material used for the shaft as given by Ndaliman (2006) and Apeh et al. (2015). $d^{3}=\frac{16}{\pi \sigma_{\text {all }}} \sqrt{\left(k_{t} T\right)^{2}+\left(k_{b} M_{b}\right)^{2}}$

Where $d$ is the diameter of the shaft $(\mathrm{m}), \sigma_{\text {all }}$ is the allowable stress of the material $\left(\mathrm{N} / \mathrm{m}^{2}\right)$ which is used for the shaft, $k_{t}(1.5)$ is the factor of safety for the stress due to torsion and $\mathrm{k}_{\mathrm{b}}(1.5)$ is the factor of safety due to bending moment as given by Apeh et al. (2015). Allowable stress of a shaft without keyway is $55 \times 10^{-}$ ${ }^{6} \mathrm{~N} / \mathrm{m}^{2}$ and shaft with keyway is $40 \times 10^{-6} \mathrm{~N} / \mathrm{m}^{2}$ Apeh et al. (2015).

The power transmitted through belt is a function of tension and speed of the belt. The power transmitted through the belt is given in Equation (8) and the power transmitted through a V-belt was determined using Equation (9) as given by Apeh et al. (2015).

$$
\begin{aligned}
& P=\left(T_{1}-T_{2}\right) \times V \\
& T_{2}=\frac{T_{1}}{e^{\mu \alpha / \frac{\sin \vartheta}{2}}} \text { for V-belt } \\
& P=T_{1}\left(1-\frac{1}{e^{\mu \alpha / \frac{\sin \theta}{2}}}\right) \times V
\end{aligned}
$$

Where $T_{1}$ is the tight tension $(\mathrm{N}), \mathrm{T}_{2}$ is the slack tension $(\mathrm{N}), \mu$ is the coefficient friction, $\alpha$ is the angle of the lap and $\theta$ is the groove angle of V-belt.

The maximum power transmitted was obtained using Equation (10) while the speed ratio is given in Equation (11) as stated by Apeh et al. (2015).

$$
P_{\max }=\left(T_{1}-\frac{T_{1}}{3}\right)\left(1-\frac{1}{e^{\mu \alpha / \frac{\sin \vartheta}{2}}}\right) \times V
$$

$N D=n d$

Where $\mathrm{N}$ is the speed of driver pulley (rpm), D is the diameter of driver pulley $(\mathrm{m}), \mathrm{n}$ is the speed of the driven pulley at the grating shaft (rpm) and $d$ is the diameter of the driven pulley $(\mathrm{m})$.

The length of the belt, $\beta, \alpha_{1}$, and $\alpha_{2}$ were determined using Equations (12), (13), (14) and 15, respectively.

$$
L=\sqrt{4 C^{2}-(D-d)^{2}}+\frac{1}{2}\left(D \alpha_{2}+d \alpha_{1}\right)
$$




$$
\begin{aligned}
& \beta=\sin ^{-1}\left(\frac{R-r}{C}\right) \\
& \alpha_{1}=180-2 \beta \\
& \alpha_{2}=180+2 \beta
\end{aligned}
$$

Where $\mathrm{L}$ is the length of the belt $(\mathrm{cm}), \mathrm{D}$ is the diameter of the driver pulley $(\mathrm{cm}), \mathrm{d}$ is the diameter of the driven pulley $(\mathrm{cm}), \mathrm{C}$ is the centre distance between the driver and driven pulleys $(\mathrm{cm}), \alpha_{1}$ is the angle of lap of driven pulley (radian), $\alpha_{2}$ is the angle of lap of the driver pulley (radian), $\mathrm{R}$ is the radius of the driver pulley $(\mathrm{cm})$ and $r$ is the radius of the driven pulley $(\mathrm{cm})$. The objective of this study was to design and fabricate a simple pedal operated cassava grater for rural dwellers.

\section{MATERIALS AND METHODS}

Design calculations for stress due to torsion, bending moment and diameter of the shaft: The material used for the fabrication of the shaft was mild steel with allowable stress of $40 \times 10^{6} \mathrm{~N} / \mathrm{m}^{2}$ for a shaft with keyway (Apeh et al., 2015). The torque that could cause twisting of the shaft for the worse scenario using a $2.5 \mathrm{HP}(1,865 \mathrm{~W})$ electric motor with a speed of 1500 rpm was calculated using equation $2(\pi=3.142)$. The maximum power output of a human is $75 \mathrm{~W}$ but this could reduce to $22 \mathrm{~W}$ with time (Akinsanmi, 1980).
The human power used for the design was $75 \mathrm{~W}$, the speed of driver pulley from the pedal is $50 \mathrm{rpm}$, the diameter of the pedal is $28 \mathrm{~cm}(0.28 \mathrm{~m})$ and diameter of the driven pulley is $6 \mathrm{~cm}(0.06 \mathrm{~m})$ by applying speed ratio using Equation (2) and the speed of the driven pulley (n) was obtained using Equation (11).

$T=\frac{60 \times 1865}{2 \times 3.142 \times 1500}=11.8714 \mathrm{Nm}$ from Equation (2) $n=\frac{50 \times 28}{6}=233.33 \mathrm{rpm} \quad$ from Equation (11)

Therefore, the torque for operating the cassava grater was determined using the following expression.

$$
T=\frac{60 \times 75}{2 \times 3.142 \times 233.33}=3.112 \mathrm{Nm} \quad \text { from Equation (2) }
$$

For the design, the highest torque from the electric motor was considered which could give the worst scenario of twisting the shaft (stress due to torsion). The bending moment resulting from the load (weight) of cassava $(2 \mathrm{~kg})$, and weight of the wooden roller $(2.5$ $\mathrm{kg}$ ) on the shaft and self-weight of the shaft $(2 \mathrm{~kg})$ was evaluated using Equation (5). Therefore, total weight (W) was $6.5 \mathrm{~kg}(63.765 \mathrm{~N})$ and length of the shaft was $0.4 \mathrm{~m}$.

$$
M_{b}=\frac{63.765 \times 0.4}{4}=6.3765 \mathrm{Nm} \quad \text { from Equation (5) }
$$

The diameter of the shaft was calculated using equation 7 as given in the following expression.

$$
d^{3}=\frac{16}{3.142 \times 42 \times 10^{6}} \sqrt{(1.5 \times 11.8714)^{2}+(1.5 \times 6.3765)^{2}}=0.000002451 \quad \text { from Equation (7) }
$$

$d=(0.000002451)^{\frac{1}{3}}=0.0135 \mathrm{~m}=14 \mathrm{~mm}$ but the diameter of $20 \mathrm{~mm}$ iron rod for the shaft was chosen for the grater.

Determination of the length of the belt for the grater: The $\beta, \alpha_{1}$, and $\alpha_{2}$ were calculated using Equations(14), (15) and (16), respectively which are needed to compute the length of the belt from equation 13 as

$$
\begin{array}{cc}
\beta=\sin ^{-1}\left(\frac{14-3}{75}\right)=8.43^{\circ} & \text { from Equation (14) } \\
\alpha_{1}=180-2 \times 8.43=163.14^{\circ}=2.85 \text { radian } & \text { from Equation (15) } \\
\alpha_{2}=180+2 \times 8.43=196.86^{\circ}=3.44 \text { radian } & \text { from Equation (16) } \\
L=\sqrt{4(75)^{2}-(28-6)^{2}}+\frac{1}{2}(28 \times 3.44-6 \times 2.85)=205.09 \mathrm{~cm} \quad \text { from Equation (13) }
\end{array}
$$

shown in the following expression when the values of $\mathrm{R}=14 \mathrm{~cm}, \mathrm{r}=3 \mathrm{~cm}, \mathrm{C}=75 \mathrm{~cm}, \mathrm{D}=28 \mathrm{~cm}$ and $\mathrm{d}$ $=6 \mathrm{~cm}$. 
The length of the chosen and used for the grater was $210 \mathrm{~cm}$ to give allowance for the adjustment of belt tension when it is necessary.

Materials used for the fabrication of the grater and description of the grater: The cassava grater was fabricated using mainly hardwood which is resistant to termite and could last longer than softwood. Hardwood could be used to fabricate cassava grater and could work effectively for a longer period of time without being attacked by termite. The frame, grating chamber (hopper), grating roller and the outlet were fabricated using hardwood. Iron rod of $20 \mathrm{~mm}$ diameter (mild steel) was used for the shaft, three roller bearings, driver and driven pulleys, belt, bicycle pedal and galvanized sheet ( $2 \mathrm{~mm}$ thick) was used for the grating surface on the grating roller. The galvanized sheet $(300$ by $600 \mathrm{~mm})$ was punched out using a 2 inches concrete nail to make the entire surface rough for scratching and grating succulent cassava tuber. The galvanized sheet was folded around the $300 \mathrm{~mm}$ diameter wooden grating roller and nailed to the wooden roller. The frame of the cassava grater was 540 wide, 1200 long and $1050 \mathrm{~mm}$ high and the grater is portable. There is a space on the frame where could be fixed to operate the cassava grater electrically or mechanically when electric motor or engine is available to power the grater. The grating chamber (hopper) was 420 by $440 \mathrm{~mm}$ at the top where the cassava is fed into the grater, 220 by $440 \mathrm{~mm}$ at the bottom and $300 \mathrm{~mm}$ high inside which the grating roller (190 mm diameter and $300 \mathrm{~mm}$ long) grate the cassava into granules. The outlet of grater below the grating chamber is inclined at an angle of $45^{\circ}$ depression to the horizontal so that the grated cassava granules could come out easily from the grating chamber. The frame and other wooden components of the grater were nailed together using 2 and 3 inches nail. The hopper (grating chamber) was fixed to the frame with 2 hinges so that it could be opened when cleaning is required after use. A hole of 10 by $30 \mathrm{~mm}$ was drilled at the centre of the slanting face of the grating chamber where a wood of 30 by 40 and 300 $\mathrm{mm}$ long was fixed for the adjustment of the clearance between the grating roller and grating chamber of the hopper. The clearance between the grating roller and the slanting face of the hopper (grating chamber) designed for could be varied between 2 and $5 \mathrm{~mm}$. A wood of 20 by 30 and $220 \mathrm{~mm}$ long was also nailed at each end of the grating chamber as a guide to prevent ungrated cassava tuber from moving to the lower chamber. The driver pulley was $280 \mathrm{~mm}$ which was connected to pedal while the driven pulley was $60 \mathrm{~mm}$ which was connected to the grating shaft. Each of the 3 bearings used has a diameter of $20 \mathrm{~mm}$ through which the shaft passed through and fixed with a key.
The bearing was put in housing and welded to an iron plate. The plate was drilled at the 2 ends and fixed to the frame with bolts and nuts. The isometric view of the cassava grater is shown in Figure 1.

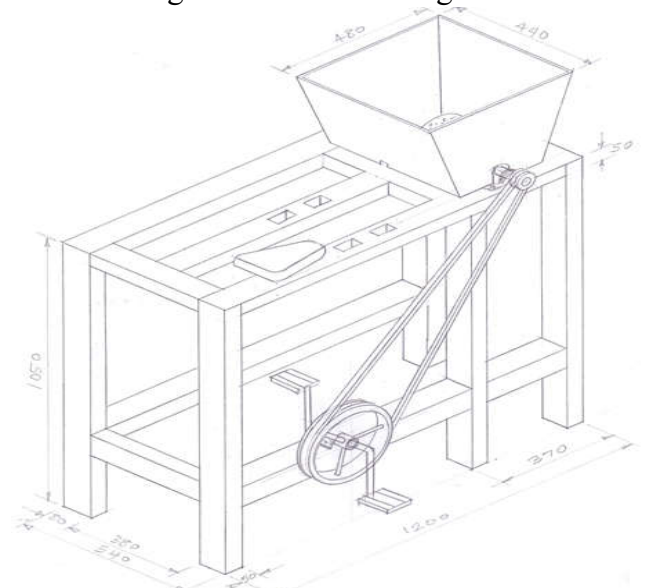

Fig 1. Isometric view of the cassava grater with dimension in $\mathrm{mm}$

Determination of the grating capacity and efficiency of the cassava grater: A $2 \mathrm{~kg}$ of peeled cassava tuber was fed into the grater through the hopper and replicated three times. The times taken to grate the tubers were 72,68 and $70 \mathrm{~s}$. The average time taken for grating 2 $\mathrm{kg}$ cassava tuber was $70 \mathrm{~s}$. The capacity of the grater for grating cassava tuber in $\mathrm{kg} / \mathrm{h}$ was calculated using Equation (17). The grated cassava was put in the muslin bag, compressed for 3 days to remove water and hydrocyanic acid from the grated cassava and for the grated cassava to ferment. After 3 days, the cassava was sieved through 1 to $2 \mathrm{~mm}$ screen. An empty plastic container was weighed as $\mathrm{M}_{1}(150 \mathrm{~g})$. The mass of cassava that passed through the sieve (screen) was put on the container and weighed in a weighing balance as $\mathrm{M}_{2}(5,150 \mathrm{~g})$. The cassava that was retained on the sieve was then put in the container and weighed as $\mathrm{M}_{3}$ $(650 \mathrm{~g})$. The grating efficiency $\left(\mathrm{E}_{\mathrm{g}}\right)$ of the grater was calculated using Equation (18).

$$
\begin{aligned}
G_{c} & =\frac{M_{c v} \times 3600}{T} \\
G_{c} & =\frac{2 \times 3600}{70}=102.9=102.9 \mathrm{~kg} / \mathrm{h} \\
E_{g} & =\frac{\left(M_{2}-M_{1}\right) \times 100}{M_{2}+M_{3}-2 M_{1}} \\
E_{g} & =\frac{(5150-150 \times 100}{5150+650-2 \times 150}=\frac{5000}{5500} \times 100=9091=90.91 \%
\end{aligned}
$$

Therefore, the grating efficiency of the grater was $90.91 \%$. The ungrated cassava is normally sundry in Nigeria as solid granular garri (koko garri) and ground 
using grinding machine as garri flour (garri lebu) which is in carbohydrate.

\section{RESULTS AND DISCUSSION}

The cassava grater was fabricated using locally available materials mainly hardwood, galvanized sheet, $20 \mathrm{~mm}$ iron rod, bicycle pedal and bearing. The pictures of the cassava grater are shown in Figures 2 and 3. The grater had grating efficiency of $90.91 \%$ as compared to $92.4 \%$ grating efficiency of an electrically operated cassava grater by Ndaliman (2006). The grating capacity of the cassava grater was found to be $102.9 \mathrm{~kg} / \mathrm{h}$. The grating capacity of the electrically operated cassava grater by Adetunji and Quadri (2011) was $158.9 \mathrm{~kg} / \mathrm{h}$ as compared to $102.9 \mathrm{~kg} / \mathrm{h}$ obtained in this study. The grating capacity of $102.9 \mathrm{~kg} / \mathrm{h}$ for the pedal operated cassava grater is adequate for rural dwellers and could eliminates finger injury when compared with the primitive hand-held scratching metal for grating cassava tuber in the rural areas.

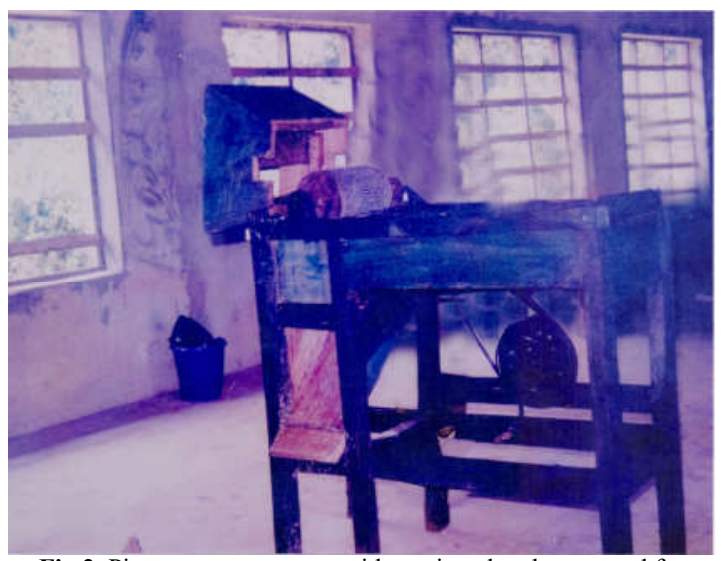

Fig 2 Picture cassava grater with grating chamber opened for visible grating roller

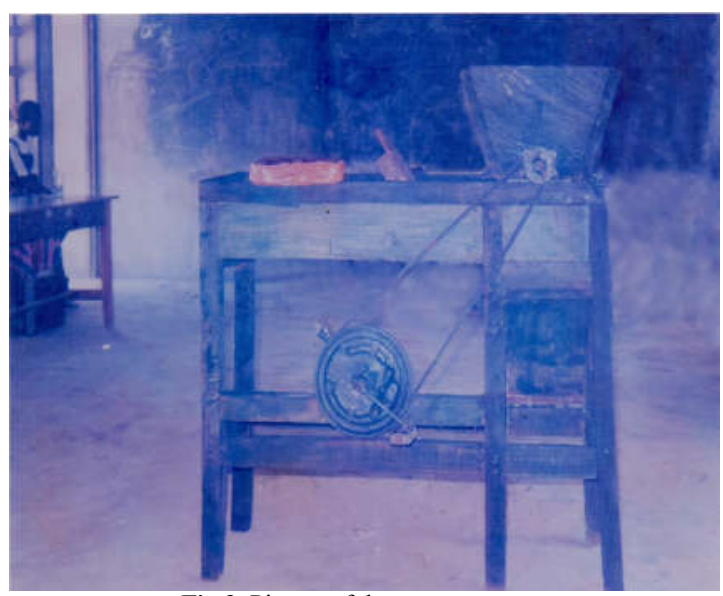

Fig 3 Picture of the cassava grater
Conclusion: A simple manually operated cassava grater was fabricated using hardwood, galvanized sheet, iron rod, bicycle pedal and bearing. The grater is effective for grating cassava tuber in rural areas where electricity, petrol and other social amenities are lacking. The grating efficiency of the cassava grater was $90.91 \%$ and the grating capacity was $102.9 \mathrm{~kg} / \mathrm{h}$. It is recommended that manually operated cassava grater be fabricated for rural women to remove drudgery and alleviate the problems associated with grating cassava tubers in the rural areas.

\section{REFERENCES}

Adetunji, OR and Quadri, AH. (2011). Design and Fabrication of an Improved Cassava Grater. The Pacific Journal of Science and Technology, 12 (2):120-129.

Akinsanmi, O (1980). Certificate agricultural science, Longman Group Ltd, London.

Apeh, FI; Yahaya, BS; Achema, F; Fabiyi, MO and Apeh, ES (2015). Design analysis of a locally fabricated palm kernel shells grinding machine. American Journal of Engineering Research, 4 (11): 01-07.

Chakraborti, M (2001). Strength of materials, $2^{\text {nd }}$ Edition. S. K. Kataria and Sons, New Delhi, 242243.

Khurmi, RS and Gupta, JK (2005). A textbook of machine design. $1^{\text {st }}$ Multicolour Edition, Eurasia Publishing House, PVT, Ltd, New Delhi, 120137.

Ndaliman, M B (2006). Development of cassava grating machine: A dual-operational mode. Leonardo Journal of Sciences, 9: 103-110.

Omoruyi, SA; Orhue, UX; Akerobo, AA and Agbimen, C I (1991). Prescribed agricultural science for senior secondary schools. Idodo Umeh Publishers Ltd, Nigeria. 